\section{JAOS JOURNAL OF APPLLED ORAL SCIENCE}

\title{
The use of a liner under different bulk-fill resin composites: 3D GAP formation analysis by $\mathrm{x}$-ray micro- computed tomography
}

\section{Abstract}

Burcu OGLAKCi ${ }^{1}$

Magrur KAZAK ${ }^{1}$

Nazmiye DONMEZ

Evrim Eliguzeloglu DALKILIC ${ }^{1}$

Safiye Selin KOYMEN ${ }^{1}$
Received: February 05, 2019 Modification: April 11, 2019 Accept: April 23, 2019
Corresponding address: Burcu Oglakci Bezmialem Vakif University Faculty of Dentistry. Department of Restorative Dentistry Istanbul - Turkey Phone: +90 $2124531850-5232288$ Fax: +902125232288 e- mail: burcu923@hotmail.com
Gap formation of composite resin restorations is a serious shortcoming in clinical practice. Polymerization shrinkage stress exceeds the tooth-restoration bond strength, and it causes bacterial infiltration within gaps between cavity walls and the restorative material. Thus, an intermediate liner application with a low elastic modulus has been advised to minimize polymerization shrinkage as well as gap formation. Objective: The purpose of this in vitro study was to assess gap formation volume in premolars restored with different bulk-fill composites, with and without a resin-modified glass-ionomer cement (RMGIC) liner, using x-ray micro-computed tomography (micro-CT). Methodology: Sixty extracted human maxillary premolars were divided into six groups according to bucco-palatal dimensions $(n=10)$. Standardized Class II mesio-occluso-distal cavities were prepared. G-Premio Bond (GC Corp., Japan) was applied in the selective-etch mode. Teeth were restored with high-viscosity (Filtek Bulk Fill, 3M ESPE, USA)-FB, sonic-activated (SonicFill 2, Kerr, USA)-SF and low viscosity (Estelite Bulk Fill Flow, Tokuyama, Japan)EB bulk-fill composites, with and without a liner (Ionoseal, Voco GmbH, Germany)-L. The specimens were subjected to 10,000 thermocycles $\left(5-55^{\circ} \mathrm{C}\right)$ and 50,000 simulated chewing cycles (100 N). Gap formation based on the volume of black spaces at the tooth-restoration interface was quantified in $\mathrm{mm}^{3}$ using micro-computed tomography (SkyScan, Belgium), and analyses were performed. Data were analyzed using repeated-measures ANOVA and the Bonferroni correction test $(p<0.05)$. Results: The gap volume of all

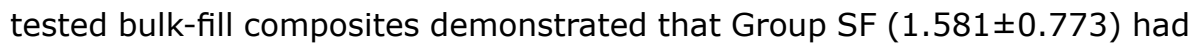

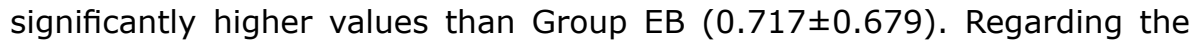
use of a liner, a significant reduction in gap formation volume was observed

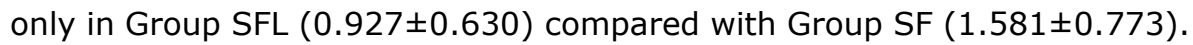
Conclusion: It can be concluded that different types of bulk-fill composite resins affected gap formation volume. Low-viscosity bulk-fill composites exhibited better adaptation to cavity walls and less gap formation than did sonic-activated bulk-fill composites. The use of an RMGIC liner produced a significant reduction in gap formation volume for sonic-activated bulk-fill composites.

Keywords: Bulk-fill composite. Gap formation. Liner. Resin-modified glass-ionomer cement. Micro-computed tomography. Micro-CT.

${ }^{1}$ Bezmialem Vakif University Faculty of Dentistry, Department of Restorative Dentistry, Istanbul, Turkey 


\section{Introduction}

Increasing demand for esthetics and improvements in adhesive system technology has made resin composite restorations a popular choice for clinicians. ${ }^{1}$ However, shrinkage associated with the polymerization of materials is a serious shortcoming in clinical practice. $^{2}$ Polymerization shrinkage stress exceeds the tooth-restoration bond strength, and it causes fluid passage and bacterial infiltration within gaps between cavity walls and the restorative material. ${ }^{3}$ Microleakage, which is described as clinically undetectable penetration, could lead to post-operative hypersensitivity, marginal staining, secondary caries, pulpal inflammation and necrosis. ${ }^{4}$

Several procedures have been developed to decrease polymerization shrinkage stress, such as modifying the chemical composition in the resin formulation, control of light irradiance, incremental layering techniques and intermediate liner application. ${ }^{5}$ However, no definitive method to eliminate polymerization shrinkage has been described in the literature. ${ }^{6}$

The incremental layering is a standard protocol used to place restorative materials in the cavity, but this technique has many disadvantages, such as placement difficulty in small cavities, increased chair time, voids and contamination risk between composite layers. ${ }^{7}$ Therefore, novel composite resin materials with the use of bulk-filling techniques have been placed on the market. ${ }^{8}$ Bulk-fill composite resins can be applied in 4-5-mm thicknesses with relative ease of use and a claim of low polymerization shrinkage compared with conventional composites. ${ }^{9}$ These materials have a short curing time due to new initiation systems and increased translucency based on reduced filler amounts and increased filler size. ${ }^{10}$ Furthermore, polymerization shrinkage stresses are reduced through the incorporation of stress-relievers; thus, they have a decreased risk of gap formation at the tooth-restoration interface. ${ }^{11}$

Gaps on the margins of the restorations may cause material deterioration and marginal infiltration. ${ }^{12}$ Although bulk-fill composite resins are claimed to exhibit low polymerization shrinkage, there is not enough information with respect to the effects of gap formation of bulk-fill composites using an intermediate liner in the literature. The use of a liner (flowable composites, resin-modified glass-ionomers, filled adhesives) with a low elastic modulus/low viscosity could provide better cavity adaptation with less gap formation as a stress-absorbing layer and lessen the polymerization shrinkage at the tooth-restoration interface. ${ }^{13}$

Currently, different types of bulk-fill composite resins that are classified according to their rheological properties are commercially available. ${ }^{14}$ For this in vitro study, high-viscosity, sonic-activated and low-viscosity bulk-fill composite resins were used. The purpose of this in vitro study was to assess the gap formation volume of maxillary premolars restored with three different types of bulk-fill resin composites, with and without a resin-modified glass-ionomer cement liner (RMGIC) as an intermediate material using microcomputed tomography.

The research null hypotheses were:

There would be no difference in the gap formation volume between different types of bulk-fill composite resins.

The RMGIC liner would not reduce gap formation volume and enhance the cavity adaptation of teeth restored with bulk-fill composite resins.

\section{Methodology}

This in vitro study was approved by the local ethics committee (process no. 06/06/2018-9063).

\section{Sample Size Calculation}

The sample size was calculated based on the estimated effect size between groups according to the literature. ${ }^{15,16}$ It was determined that 10 samples were needed for each group to achieve a medium effect size $(d=0.50)$, with $80 \%$ power and a $5 \%$ type 1 error rate in this study.

\section{Specimen Preparation}

A total of 60 intact human maxillary premolar teeth, freshly extracted for orthodontic and periodontal purposes, were selected. To standardize the dimensions of the teeth before the study, the maximum buccopalatal width (BPW) of each tooth was measured using a digital micrometer. ${ }^{17}$ Then, the teeth were allocated into six groups according to the BPW $(n=10)$. The mean bucco-palatal dimensions of the teeth between groups differed no more than $5 \%(p=0.061)$ according to one-way ANOVA using the Statistical Package for Social Sciences 22.0 for Windows software (SPSS 22.0 for Windows, SPSS Inc., Chicago, IL, US) $(p<0.05)$. 
The teeth were embedded in acrylic resin blocks with the crown extended to $2 \mathrm{~mm}$ from the cementoenamel junction (CEJ) along the vertical axis.

A standardized Class II mesio-occluso-distal (MOD) cavity was opened in each tooth (Figure 1) using a coarse diamond fissure bur (FC Diamond, GZ Instrumente, Austria) in a high-speed handpiece under water cooling. A new bur was employed for each of the five specimens. The dimensions of the approximal box of each cavity were arranged such that they were two-thirds of the BPW of the tooth (A), and the occlusal isthmus was arranged to half of the BPW (B). The total depth of the cavity was adjusted to $4 \mathrm{~mm}$, with an axial wall height of $2 \mathrm{~mm}$. Approximal boxes had $1.5 \mathrm{~mm}$ mesiodistal width on the gingival floors $1 \mathrm{~mm}$ above the CEJ. ${ }^{18}$ The dimensions of cavity preparation were confirmed with a digital caliper. The specimens were then stored in distilled water at room temperature $\left(23 \pm 1^{\circ} \mathrm{C}\right)$ before and after preparation.

\section{Restorative Procedure}

After cavity preparations, a metal auto matrix (SuperMat ${ }^{\top M}$ assorted kit, Kerr Corp., Orange, USA) was placed around the tooth. The enamel margins of the cavities were etched with $37 \%$ phosphoric acid for $15 \mathrm{~s}$, rinsed with water for $5 \mathrm{~s}$ and gently air-dried. Then, a single-component universal adhesive system, G-Premio Bond (GC Corp., Japan) was applied with a microbrush for $10 \mathrm{~s}$, followed by air-thinning for $5 \mathrm{~s}$ under maximum air pressure and curing with a light-emitting diode light curing unit (LED LCU) (Valo, Ultradent, South Jordan, UT, USA) (irradiance of 1000 $\mathrm{mW} / \mathrm{cm}^{2}$ ). The light intensity was controlled during the whole process using a radiometer (Demetron LED Radiometer, Kerr Corp.). The materials used in this study are summarized in Figure 2.

Group Filtek Bulk Fill (FB)

High-viscosity bulk-fill resin composite (Filtek ${ }^{\text {TM }}$ Bulk Fill, A2 Shade, 3M ESPE, USA) was used to restore the cavity and was polymerized with an LED LCU from the occlusal surface for $10 \mathrm{~s}$. After removing the metal matrix, the restorations were polymerized from the mesial and distal surfaces for $10 \mathrm{~s}$ on each side.

Group Filtek Bulk Fill with liner (FBL)

The cavities were lined with one-component RMGIC (Ionoseal, Voco $\mathrm{GmbH}$, Germany) liner, approximately $1 \mathrm{~mm}$ thick, on the pulpal and axial walls and lightcured with an LED LCU for 20 s. G-Premio Bond was applied in the selective-etch mode as previously described, and the cavity was restored with Filtek $^{\mathrm{TM}}$ Bulk Fill resin composite as described for group FB.

\section{Group SonicFill 2 (SF)}

Sonic-activated high-viscosity bulk-fill resin composite (SonicFill ${ }^{\mathrm{TM}}$ 2, A2 Shade, Kerr Corp.) was used to restore the cavity with a sonic hand-piece and polymerized with an LED LCU for $20 \mathrm{~s}$. After removing the metal matrix, the restorations were polymerized from the mesial and distal surfaces for $10 \mathrm{~s}$ on each side.

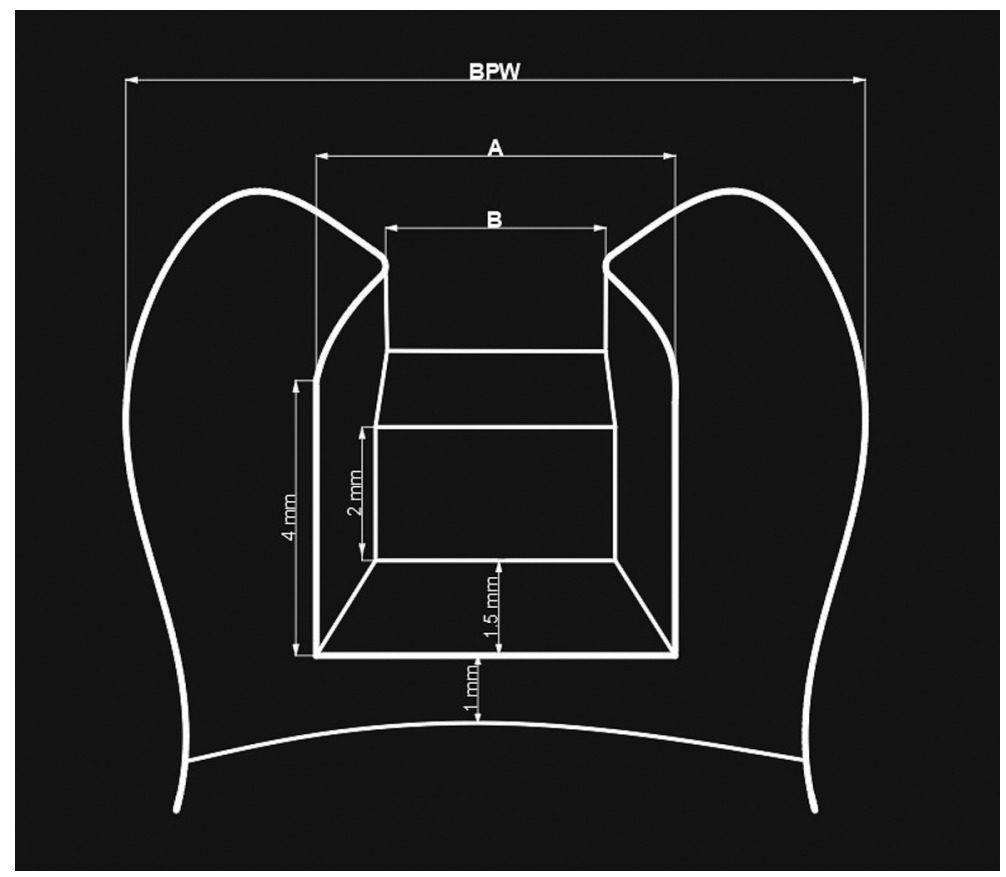

Figure 1- Schematic diagram of the MOD cavity design. Bucco-palatal width (BPW), gingival floor width $(A=2 / 3 \mathrm{BPW})$, occlusal isthmus width $(B=1 / 2$ BPW $)$ 


\section{Group SonicFill 2 with liner (SFL)}

The cavities were lined with RMGIC liner, polymerized as described in group FBL. G-Premio Bond was applied as previously described and then restored with SonicFill ${ }^{\mathrm{TM}} 2$ resin composite as described in group SF.

\section{Group Estelite Bulk Fill Flow (EB)}

Low-viscosity bulk-fill resin composite (Estelite Bulk Fill Flow, A2 Shade, Tokuyama Dental Corp., Japan) was used to restore the cavity, and it was polymerized with an LED LCU for $10 \mathrm{~s}$. After removing the metal matrix, the restorations were polymerized from the mesial and distal surfaces for $10 \mathrm{~s}$ on each side.

\section{Group Estelite Bulk Fill Flow with liner (EBL)}

The cavities were lined with a RMGIC liner and polymerized as described for group FBL. G-Premio Bond was applied as previously described, followed by restoration with Estelite Bulk Fill Flow as described for group EB.

All restorations were finished with an extra-fine diamond bur (FC Diamond, GZ Instrumente, Austria) with a high-speed handpiece under water cooling and polished with aluminum oxide polishing disks (Sof-Lex, 3M ESPE, USA) in a slow hand-piece according to the manufacturer's instructions.

\section{Aging Procedure}

All restored teeth were thermocycled (SD Mechatronik Termocycler THE-1100, FeldkirchenWesterham, Germany) for 10,000 cycles between $5^{\circ} \mathrm{C}$ and $55^{\circ} \mathrm{C}$ with a dwell time of $30 \mathrm{~s}$ and a transfer time of $10 \mathrm{~s}$. Then, the specimens were fixed to a chewing simulator (CS-4.2; SD Mechatronik, FeldkirchenWesterham, Germany) and subjected to 50,000 cycles $(100 \mathrm{~N}$ and $1.7 \mathrm{~Hz})$ at room temperature $\left(23 \pm 1^{\circ} \mathrm{C}\right)$ and $100 \%$ humidity. A vertical load was applied with a 3.2-mm stainless-steel ball-shaped stylus at the center of the restorations. ${ }^{19}$ During the aging procedure, the specimens remained immersed in distilled water.

\section{Micro-Computed Tomography (micro-CT) Analysis}

Gap formation analysis was performed with the microtomography system SkyScan 1174v2 (Skyscan, Kartuizersweg, Kontich, Antwerp, Belgium). The microfocus $X$-ray source was set at $50-k V p$ accelerating voltage, $40 \mathrm{~W}$ and $800 \mu \mathrm{A}$ beam current, and a 0.5 $\mathrm{mm}$ aluminum filter was applied. The specimens were scanned at a $14.46 \mu \mathrm{m}$ pixel size at $1024 \times 1304$

\begin{tabular}{|c|c|c|c|c|}
\hline $\begin{array}{l}\text { Adhesive } \\
\text { Systems }\end{array}$ & $\begin{array}{l}\text { G-Premio BOND } \\
\qquad(\mathrm{pH}=1.5)\end{array}$ & $\begin{array}{c}\text { GC Corp. } \\
\text { (Tokyo, Japan) }\end{array}$ & 1707242 & $\begin{array}{l}\text { 4-MET, 10-MDP, MDTP, phosphoric acid ester monomer, } \\
\text { thiophosphate monomer, dimethacrylate, butylated hydroxytoluene, } \\
\text { acetone, water, photoinitiator, silicon dioxide. }\end{array}$ \\
\hline \multirow{3}{*}{$\begin{array}{l}\text { Composite } \\
\text { Resins }\end{array}$} & $\begin{array}{l}\text { Filtek }^{\mathrm{TM}} \text { Bulk Fill } \\
\text { (A2 Shade) }\end{array}$ & $\begin{array}{l}\text { 3M ESPE, } \\
\text { (St Paul MN, } \\
\text { USA) }\end{array}$ & N853695 & $\begin{array}{l}\text { Organic Matrix Composition : AUDMA, UDMA and 1,12-dodecane- } \\
\text { DMA. } \\
\text { Inorganic Filler Particulate: ( } 76.5 \mathrm{wt} \% / 58.4 \mathrm{vol} \% \text { ) non-aggregated } \\
4 \text { to } 11 \mathrm{~nm} \text { zirconia filler aggregated zirconia/silica cluster filler } \\
\text { (comprised of } 20 \mathrm{~nm} \text { silica and } 4 \text { to } 11 \mathrm{~nm} \text { zirconia particles) } \\
\text { ytterbium trifluoride filler ( } 100 \mathrm{~nm}) \text { non-aggregated } 20 \mathrm{~nm} \text { silica filler }\end{array}$ \\
\hline & $\begin{array}{l}\text { SonicFill }{ }^{\mathrm{TM}} 2 \\
\text { Bulk Fill } \\
\text { (A2 Shade) }\end{array}$ & $\begin{array}{l}\text { Kerr Corp. } \\
\text { Orange, } \\
\text { (CA, USA) }\end{array}$ & 6421421 & $\begin{array}{l}\text { Organic Matrix Composition: AUDMA, UDMA and 1,12-dodecane- } \\
\text { DMA, camphoroquinone. } \\
\text { Inorganic Filler Particulate :(82 wt } \%, 68.5 \text { vol\%) } \\
10-30 \text { wt } \% \text { Poly (oxy-1,2 ethanediyl), } \alpha, \alpha^{\prime}-[(1-\text {-methylethylidene }) \text { di- } \\
4,1 \text { phenylene] bis [ } \omega-[(2-\text { methyl }-1 \text { - oxo-2- propenyl)oxy] }-0.1-1 \% \\
2,2 \text { - ethylenedioxydiethyl dimethacrylate }\end{array}$ \\
\hline & $\begin{array}{l}\text { Estelite Bulk Fill } \\
\text { Flow } \\
\text { (A2 Shade) }\end{array}$ & $\begin{array}{l}\text { Tokuyama Dental } \\
\text { Corp, } \\
\text { (Tokyo, Japan) }\end{array}$ & O1OE17 & $\begin{array}{l}\text { Organic Matrix Composition: Bis-GMA, Bis-MPEPP, TEGDMA } \\
\text { Inorganic Filler Particulate:( } 70 \mathrm{wt} \% / 56 \text { vol\%) } \\
\text { Supra-Nano Spherical filler }\left(200 \mathrm{~nm} \text { spherical } \mathrm{SiO}_{2}-\mathrm{ZrO}_{2}\right) \\
\text { - Composite Filler (include } 200 \mathrm{~nm} \text { spherical } \mathrm{SiO}_{2}-\mathrm{ZrO}_{2}\end{array}$ \\
\hline Acid & $\begin{array}{l}\text { Scotchbond }^{\mathrm{TM}} \\
\text { Universal } \\
\text { Etchant }\end{array}$ & $\begin{array}{l}\text { 3M ESPE (St. } \\
\text { Paul,MN,USA.) }\end{array}$ & 614453 & $37 \%$ phosphoric acid, $60 \%$ water, $5 \%$ synthetic amorphous silica \\
\hline $\begin{array}{l}\text { Resin } \\
\text { Modified } \\
\text { Glass } \\
\text { lonomer }\end{array}$ & lonoseal & $\begin{array}{l}\text { Voco GmbH } \\
\text { (Cuxhoven, } \\
\text { Germany) }\end{array}$ & 1749506 & Bis-GMA, diurethanedimethacrylate, BHT and glass ionomer \\
\hline
\end{tabular}

Abbreviations: 4-MET, 4-[2-(methacryloyloxy)ethoxycarbonyl] phthalic acid; MDTP, 1-methyl-4-phenyl-1,2,3,6-tetrahydropyridine; 10MDP, 10-methacryloyloxydecyl dihydrogen phosphate; AUDMA, aromatic urethane dimethacrylat; UDMA, urethane dimethacrylate; DMA, dimethylacetamide; wt $\%$, weight percentage; vol\%, volume percentage; nm, nanometer; Bis-GMA, bisphenol A glycidyl methacrylate; Bis-MPEPP, bis-methacryloxyethoxy phenyl propane; TEGDMA, triethylene glycol dimethacrylate; mm,micrometer; BHT, butyl hydroxyl toluene.

Figure 2- Material brand names/ manufacturers, batch numbers and chemical compositions 
resolution with an exposure time of $7500 \mathrm{~ms}$. The total number of slices averaged 360 , with an average scanning time close to $50 \mathrm{~min}$. For each sample, 360 raw data points were recorded, and, after reconstruction, 655 transverse tomographic sections were obtained using NRecon (Version 1.6.10.2, Skyscan, Kontich) software.

Image analyses of gap formation based on the volume of black spaces were conducted with the three-dimensional (3D) analysis tool from CTAn (CT-Analyser software Version 1.16.4.1; Skyscan, Kontich). Black spaces were present in the volume of interest (VOI), which originated from whole twodimensional (2D) images within the region of interest (ROI). All evaluations were performed with the VOI achieved from the ROI centered on the delimitations of the restorative materials. 3D images were obtained by CTvox (Version 3.1.1 r1191, Skyscan, Kontich). ${ }^{15}$ The volume of gap formation was calculated through analysis of the tooth-restoration interface and is described in $\mathrm{mm}^{3}$.

\section{Statistical Analysis}

Statistical analysis was performed using SPSS 22.0 for Windows (SPSS Inc., Chicago, IL, USA). The gap formation data were first analyzed for normality of variables with the Shapiro-Wilk test, and Levene's test was used to show homogeneity of variances. These data were normally distributed. Repeatedmeasures ANOVA was used to compare withinand between-group differences in gap formation. Pairwise comparisons were performed with Bonferroni correction. Statistical significance was determined at a confidence level of 0.05 in all analyses.

\section{Results}

The obtained data were assessed based on the recorded volume $\left(\mathrm{mm}^{3}\right)$. An analysis of the gap formation between bulk-fill composites and/or the RMGIC liner and cavity walls was performed for all tested groups $(n=10)$. Micro-CT-based gap formation volumes with standard deviations are shown in Figure 3. The representative two-dimensional (2D) and three-dimensional (3D) images of all tested bulk-fill composites by micro-computed tomography (micro-CT) are shown in Figure 4. Group SF showed a significantly higher gap formation volume than Group EB $(p<0.05)$. There were no statistically significant differences between Group EB and Group FB ( $p>0.05$ ).

In addition, within the groups with a liner, no significant differences were found between Group FBL, Group SFL and Group EBL $(p>0.05)$. When comparing the groups restored with the same bulkfill composites regarding the use of a liner, Group SFL showed significantly lower gap formation volumes than Group SF (Figure 5) $(p<0.05)$. There were no statistically significant differences between Group FB and Group FBL or Group EB and Group EBL ( $p>0.05$ ).

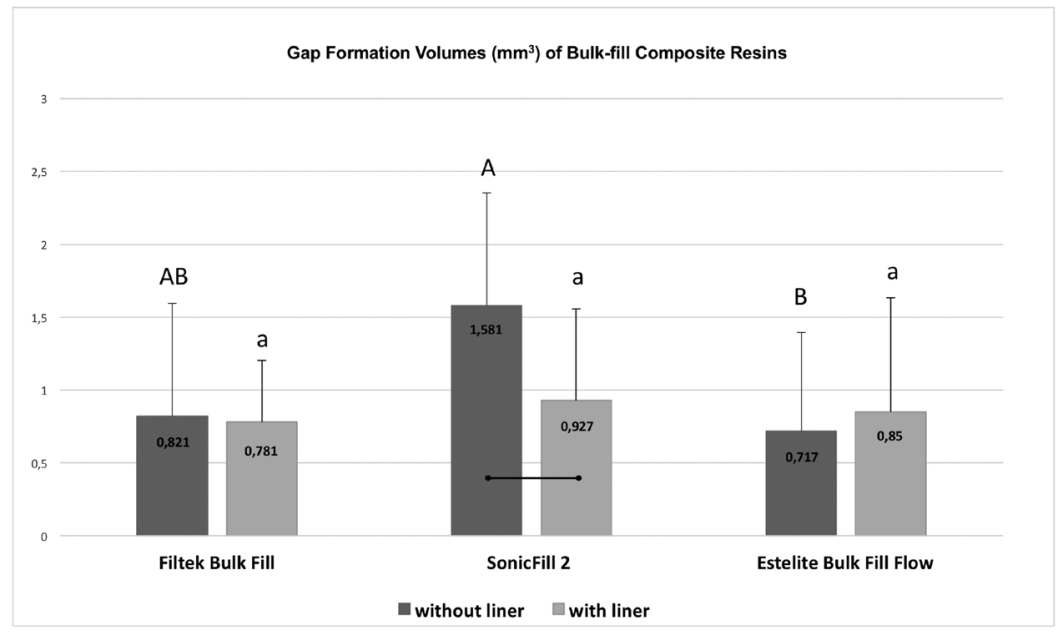

*Different letters indicate that there was statistically significant differences in mean gap formation volumes with standard deviations for bulk-fill composites without liner/with liner $(p<0.05)$.

**Horizontal bars indicate that there was statistically significant differences in mean gap formation volume with standard deviations for same bulk-fill composites according to the use of liner $(p<0.05)$.

Figure 3- Micro-CT-based gap formation volumes with standard deviations $\left(\mathrm{mm}^{3}\right)$ of all tested groups $(\mathrm{n}=10)$ 


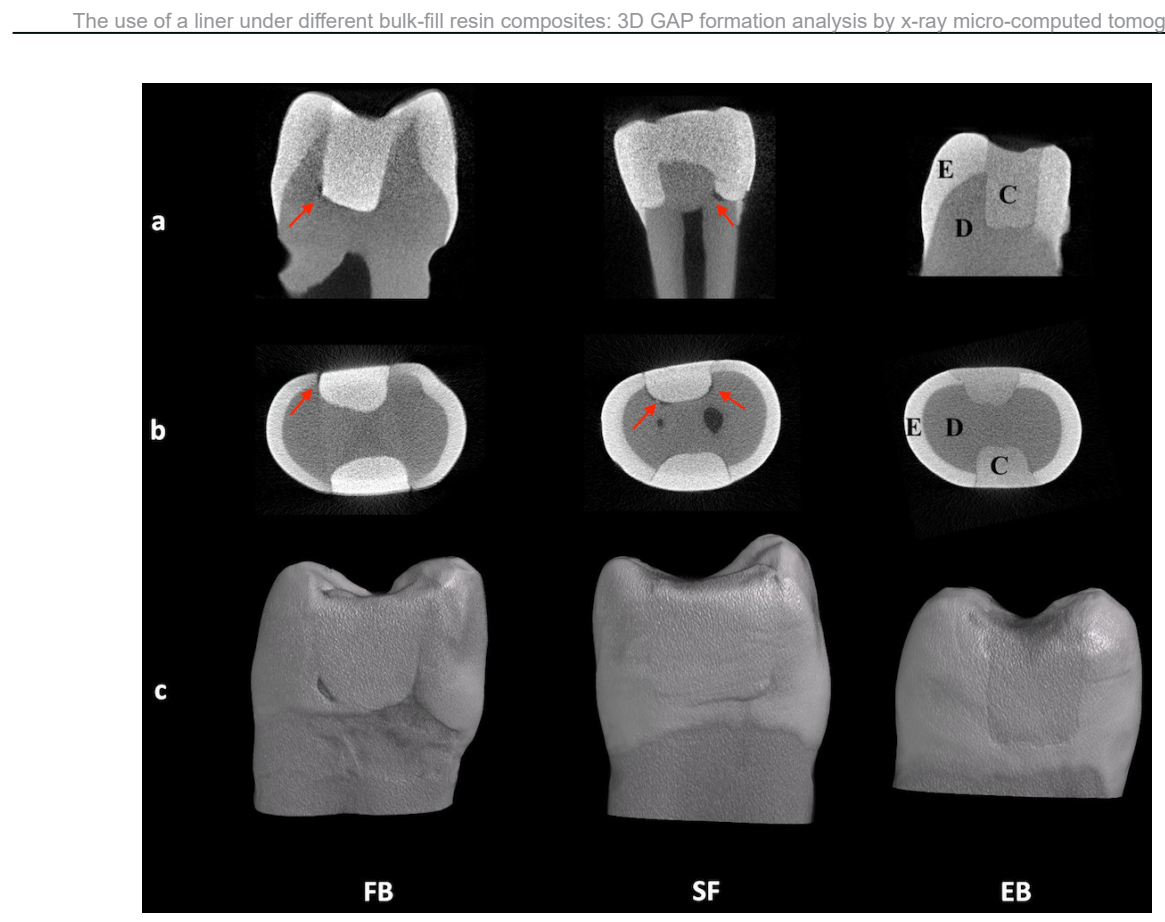

Figure 4- Representative two-dimensional (2D) and three-dimensional (3D) images of all tested bulk-fill composites by micro-CT. The gap formations are detected between teeth and restorations (arrows). Illustrative 2D images of the specimens are visualized: sagittal section (a) and axial section (b). 3D volume rendering of the specimens (c). E, enamel; D, dentin; C, composite; FB, Filtek Bulk Fill; SF, SonicFill 2; EB, Estelite Bulk Fill Flow

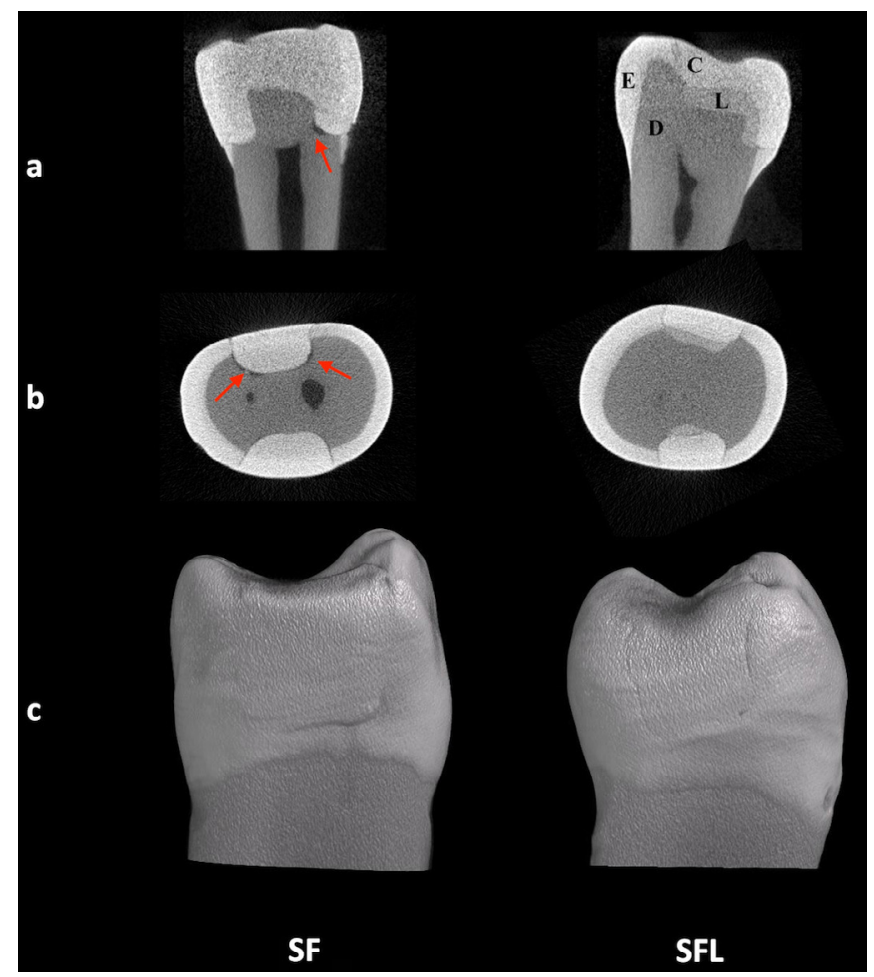

Figure 5- Representative two-dimensional (2D) and three-dimensional (3D) images of sonic-activated bulk-fill composites by micro-CT. Presence of gap formation is noted at the tooth-restoration interface (arrows). Illustrative 2D images of the specimens are visualized: sagittal section (a) and axial section (b). 3D volume rendering of the specimens (c). E, enamel; D, dentin; C, composite; SF, SonicFill 2; SFL, SonicFill 2 with liner

\section{Discussion}

The gap formation volume of teeth restored with different types of bulk-fill composites, with and without a RMGIC liner, was evaluated. Based on the results of this study, the first null hypothesis, which proposed that there would be no difference in the gap formation volume between different types of bulk-fill composites, was rejected. The low-viscosity bulk-fill composites exhibited lower gap formation volumes than the other tested bulk-fill composites. The second null hypothesis, which proposed that a RMGIC liner would reduce gap 
formation volume and enhance the cavity adaptation of teeth restored with bulk-fill composites, was partially rejected. When an RMGIC liner was used under all tested bulk-fill composites, a significant reduction in gap formation was identified for sonic-activated bulkfill composites.

Gap formation is one of the most common issues associated with composite resin restorations. ${ }^{20}$ Gaps can originate from various factors, including inadequate adhesion at the tooth-restoration interface due to polymerization shrinkage, adhesive resin degradation with insufficient light-curing, fatigue resulting from the aging procedure, differences in the coefficients of thermal expansion of the tooth substrate and composite resin, the finishing and polishing procedure, and lack of restorative material placement in the cavity. ${ }^{21}$

Several in vitro methods are available to assess the gap formation of restorations, such as dye penetration, air pressure, fluid filtration, optical coherence tomography (OCT) and X-ray microcomputed tomography (micro-CT). ${ }^{22}$ Conventional methods (i.e., dye penetration) are destructive due to the need to section the specimens and are semi-quantitative, based on visual evaluations by the operator. Furthermore, they do not represent the entire gap formation areas. ${ }^{23}$ To overcome these drawbacks, a novel methodology, micro-CT, has been introduced as an imaging device, with its origins in the further development of conventional computed tomography. ${ }^{24}$ This device can provide 2D and 3D images of gap/void formation in restored teeth due to the penetrating capacity of $\mathrm{X}$-rays ${ }^{24}$ and is a powerful method for ensuring the acquisition of precise information that would allow clinicians to analyze the area without destroying the specimens. ${ }^{25}$

In this study, micro-CT imaging was used to quantify the gap formation between the cavity walls and restorative materials as the volume $\left(\mathrm{mm}^{3}\right)$ after a thermo-mechanical aging procedure. Thermocycling and mechanical aging are the most effective and frequently used methods for imitating clinical situations. ${ }^{26}$ Thermocycling is a water storage protocol that subjects specimens to the extreme temperature differences present in the oral cavity due to hot or cold drinks, inducing the composite resin to contract and expand several times for hydrolytic degradation. ${ }^{27}$ Mechanical aging is performed to simulate the exposure of the tooth-restoration interface to cyclic subcritical loadings produced during chewing. ${ }^{28}$ In the current study, all restored teeth were subjected to 10,000 thermocycles $\left(5-55^{\circ} \mathrm{C}\right)$, which represents 1 year of clinical functions, ${ }^{29}$ and 50,000 simulated chewing cycles (100 N loading).

Significantly higher gap formation volumes were found for Group SF compared with Group EB among all tested bulk-fill composites. In contrast to this finding, Han, et al. ${ }^{16}$ (2017) reported that low-viscosity bulkfill composites showed a higher gap formation volume compared with sonic-activated and high-viscosity bulkfill composites. Additionally, Jung and Park ${ }^{30}$ (2017) and Hayashi, et al. ${ }^{31}$ (2019) reported that high-viscosity bulk-fill composites showed better marginal adaptation than low-viscosity bulk-fill composites. Alqudaihi, et al. $^{32}$ (2019) stated that no significant differences were found between different types of bulk-fill composites with respect to cavity adaptation. Estelite Bulk Fill Flow has lower filler content (70 wt\%/56 vol\%) associated with the high percentage of organic matrix compared with Filtek Bulk Fill (76.5 wt\%/ 58.4 vol\%) and SonicFill ${ }^{\mathrm{TM}} 2$ (82 wt\%/68.5 vol\%). Furthermore, it is well known that flowable composite resins may provide better adaptation to the cavity walls due to their lower viscosity. ${ }^{33}$ Therefore, this finding can be explained by the lower filler content of this material and new filler technology (spherical filler) present in its inorganic matrix. SonicFill ${ }^{T M} 2$ Bulk Fill utilizes sonic energy with a blend of low-viscosity composite and universal composite. It is composed of high filler content and different monomers (AUDMA, UDMA) that decrease the polymerization shrinkage of the material. In addition, it can provide better adaptation to cavity walls, behaving like a flowable composite during placement. ${ }^{34}$ However, a few studies ${ }^{35,36}$ have reported that of the previous generation of sonic-activated bulk-fill composites, SonicFill ${ }^{\mathrm{TM}}$ did not provide better adaptation to cavity walls compared with conventional composites. In this study, despite the use of a newgeneration sonic-activated bulk-fill composite with a new filler technology (zirconium oxide and silica oxide particles), similar gap formation volumes to those in other studies ${ }^{35,36}$ were obtained in Group SF. Moreover, this finding can be explained by the longterm thermocycling, in addition to mechanical aging, unlike in previous studies. ${ }^{35,36}$ As a consequence, the aging procedure resulted in deterioration at the toothrestoration interface.

An intermediate liner application with a low 
elastic modulus has been recommended to reduce polymerization shrinkage as well as gap formation of composite resins. ${ }^{37} \mathrm{Nie}$, Yap, Wang ${ }^{38}$ (2018) reported that reduced gap formation was observed when an intermediate liner was used under conventional composite resins, based on the improved cavity adaptation and stress absorbing capacity. Nevertheless, Alomari, Reinhardt, Boyer ${ }^{39}$ (2001) determined no differences in gap formation between the restorations with and without a liner. Although manufacturers claim that bulk-fill composites show lower polymerization shrinkage than conventional composites, there is not enough information in the literature regarding gap formation of bulk-fill composites when intermediate liners are used.

In the present study, gap formations of different bulk-fill composites with and without a resin-modified glass-ionomer cement (RMGIC) liner were evaluated. Among all the tested groups, the RMGIC liner produced a significant reduction in gap formation only in group SFL compared with group SF. Han, et. al. ${ }^{40}$ (2019) reported that cavity adaptation increased when an intermediate liner (Fuji Lining LC, GC Corp.) was used under high-viscosity bulk-fill composite resin (Tetric EvoCeram Bulk Fill, Ivoclar Vivadent). This finding can be explained by the different chemical composition of the materials used in both studies and cavity configuration. In addition, it was determined that SonicFill ${ }^{\mathrm{TM}} 2$ Bulk Fill showed the highest gap formation volume among all the tested bulk-fill composites in this study. Thus, the RMGIC liner, due to its low elastic modulus, significantly decreased gap formation and facilitated cavity adaptation of this material. As a consequence, the use of an RMGIC liner could be recommended when sonic-activated bulk-fill composites are utilized.

\section{Conclusions}

Regarding the limitations of this study, only one type of intermediate liner (RMGIC) was investigated to evaluate the effects on gap formation under bulk-fill resin composite restorations. In addition, a conventional composite used as a control group was needed for comparison with the bulk-fill composites. Thus, further studies should focus on the effects of different intermediate liners, such as the RMGIC liner (Vitrebond, 3M ESPE) or flowable resin composite, under both bulk-fill and conventional composite restorations.

Within the limitations of the present study, it can be concluded that:

Different types of bulk-fill composites affected the gap formation volume. Low-viscosity bulk-fill composites showed better cavity adaptation and less gap formation than sonic-activated bulk-fill composites.

The use of an RMGIC liner yielded a significant reduction in gap formation volume for only sonicactivated bulk-fill composites.

\section{References}

1- Cobb DS, MacGregor KM, Vargas MA, Denehy GE. The physical properties of packable and conventional posterior resin-based composites: a comparison. J Am Dent Assoc. 2000;131(11):1610-5. 2- Causton BE, Miller B, Sefton J. The deformation of cusps by bonded posterior composite restorations: an in vitro study. $\mathrm{Br}$ Dent J. 1985;159(12):397-400.

3- Araujo FO, Vieira LC, Monteiro S Junior. Influence of resin composite shade and location of the gingival margin on the microleakage of posterior restorations. Oper Dent. 2006;31(5):556-61.

4- Kidd EA. Microleakage: a review. J Dent.1976;4(5):199-206.

5- Rosatto CMP, Bicalho AA, Veríssimo C, Bragança GF, Rodrigues MP, Tantbirojin D, et al. Mechanical properties, shrinkage stress, cuspal strain and fracture resistance of molars restored with bulk-fill composites and incremental filling technique. J Dent. 2015;43(12):1519-28. doi: 10.1016/j.jdent.2015.09.007

6- Münchow EA, Meereis CT, Oliveira da Rosa WL, Silva AF, Piva E. Polymerization shrinkage stress of resin-based dental materials: A systematic review and meta-analyses of technique protocol and photoactivation strategies. J Mech Behav Biomed Mater.2018;82:77-86. doi: 10.1016/j.jmbbm.2018.03.004

7- Marovic D, Tauböck TT, Attin T, Panduric V, Tarle. Monomer conversion and shrinkage force kinetics of low-viscosity bulk-fill resin composites. Acta Odontol Scand. 2015;73(6):474-80. doi: 10.3109/00016357.2014.992810

8- Czasch P, Ilie N. In vitro comparison of mechanical properties and degree of cure of bulk fill composites. Clin Oral Investig. 2013;17(1):227-35. doi: 10.1007/s00784-012-0702-8

9- Jang JH, Park SH, Hwang IN. Polymerization shrinkage and depth of cure of bulk-fill resin composites and highly filled flowable resin. Oper Dent. 2015;40(2):172-80. doi: 10.2341/13-307-L

10- Lassila LV, Nagas E, Vallittu PK, Garoushi S. Translucency of flowable bulk-filling composites of various thicknesses. Chin J Dent Res. 2012;15(1):31-5.

11- Kapoor N, Bahuguna N, Anand S. Influence of composite insertion technique on gap formation. J Conserv Dent. 2016;19(1):77-81. doi: 10.4103/0972-0707.173205

12- Opdam NJ, Roeters JJ, Peters TC, Burgersdijk RC, Teunis M. Cavity wall adaptation and voids in adhesive class I resin composite restorations. Dent Mater. 1996;12(4):230-5.

13- Cara RR, Fleming GJ, Palin WM, Walmsley AD, Burke FJ. Cuspal deflection and microleakage in premolar teeth restored with resinbased composites with and without an intermediary flowable layer. J Dent. $2007 ; 35(6): 482-9$. 
14- Vandewalker JP, Casey JA, Lincoln TA, Vandewalle KS. Properties of dual-cure, bulk-fill composite resin restorative materials. Gen Dent. 2016; 64(2):68-73.

15- Almeida LJ Jr, Penha KJ, Souza AF, Lula EC, Magalhaes FC, Lima $\mathrm{DM}$, et al. Is there correlation between polymerization shrinkage, gap formation, and void in bulk fill composites? A $\mu \mathrm{CT}$ study. Braz Oral Res. 2017;18(31):e100. doi: 10.1590/1807-3107bor-2017.vol31.0100 16- Han SH, Park SH. Comparison of internal adaptation in class II bulkfill composite restorations using micro-CT. Oper Dent. 2017;42(2):20314. doi: 10.2341/16-023-L

17- Karaman E, Ozgunaltay G. Cuspal deflection in premolar teeth restored using current composite resins with and without resinmodified glass ionomer liner. Oper Dent. 2013;38(3):282-9. doi: 10.2341/11-400-L

18- Tekce N, Pala K, Demirci M, Tuncer S. Influence of different composite materials and cavity preparation designs on the fracture resistance of mesio-occluso-distal inlay restoration. Dent Mater J. 2016;35(3):523-31. doi: 10.4012/dmj.2015-287

19- Oliveira Lino LF, Machado CM, Paula VG, Vidotti HA, Coelho PG, Benalcazar Jalkh EB. Effect of aging and testing method on bond strength of CAD/CAM fiber-reinforced composite to dentin. Dent Mater. 2018;34(11):1690-701. doi: 10.1016/j.dental.2018.08.302 20- Duquia Rde C, Osinaga PW, Demarco FF, De V Habekost L, Conceição EN. Cervical microleakage in MOD restorations: in vitro comparison of indirect and direct composite. Oper Dent. 2006;31(6):682-7.

21- Kwon Y, Ferracane J, Lee IB. Effect of layering methods, composite type, and flowable liner on the polymerization shrinkage stress of light cured composites. Dent Mater. 2012; 28(7):801-9. doi: 10.1016/j. dental.2012.04.028

22- Yilmaz F, Gonulol N, Guler E, Ersoz E, Aytac F. Effects of different light sources on microleakage of composite resins with different monomer structures. J Dent Sci. 2014;9(4):364-70. https://doi. org/10.1016/j.jds.2013.01.009

23- Tay FR, Suh BI, Pashley DH, Prati C, Chuang SF, Li F. Factors contributing to the incompatibility between simplified-step adhesives and self-cured or dual-cured composites. part II. single-bottle, totaletch adhesive. J Adhes Dent. 2003;5(2):91-105.

24- Hirata R, Clozza E, Giannini M, Farrokhmanesh E, Janal M, Tovar $\mathrm{N}$, et al. Shrinkage assessment of low shrinkage composites using microcomputed tomography. J Biomed Mater Res B Appl Biomater. 2015;103(4):798-806. doi: 10.1002/jbm.b.33258

25- Sampio CS, Chiu KJ, Farrokmanesh E, Janal M, Puppin-Rontani RM, Giannini M, et al. Microcomputed tomography evaluation of polymerization shrinkage of class I flowable resin composite restorations. Oper Dent. 2017;42(1):E16-23. doi: 10.2341/15-296-L 26- Van Meerbeek B, Peumans M, Poitevin A, Mine A, Van Ende $A$, Neves $A$, et al. Relationship between bond-strength tests and clinical outcomes. Dent Mater. 2010;26(2):e100-21. doi: 10.1016/j. dental.2009.11.148

27- Xie C, Han Y, Zhao XY, Wang ZY, He HMI. Microtensile bond strength of one- and two-step self-etching adhesives on sclerotic dentin: the effects of thermocycling. Oper Dent. 2010;35(5):547-55. doi: $10.2341 / 10-025-1$
28- De Munck J, Van Landuyt K, Peumans M, Poitevin A, Lambrechts P, Braem $M$, et al. A critical review of the durability of adhesion to tooth tissue: methods and results. J Dent Res. 2005;84(2):118-32.

29- Morresi AL, D'Amario M, Capogreco M, Gatto R, Marzo G, $D^{\prime}$ Arcangelo $C$, et al. Thermal cycling for restorative materials: does a standardized protocol exist in laboratory testing? A literature review. J Mech Behav Biomed Mater. 2014;29:295-308. doi: 10.1016/j. jmbbm.2013.09.013

30- Jung JH, Park SH. Comparison of polymerization shrinkage, physical properties, and marginal adaptation of flowable and restorative bulk fill resin-based composites. Oper Dent. 2017;42(4):375-86. doi: 10.2341/16-254-L.

31-Hayashi J, Espigares J, Takagaki T, Shimada Y, Tagami J, Numata $\mathrm{T}$, et al. Real-time in-depth imaging of gap formation in bulk-fill resin composites. Dent Mater. 2019;35(4):585-96. doi: 10.1016/j. dental.2019.01.020

32- Alqudaihi FS, Cook NB, Diefenderfer KE, Bottino MC, Platt JA. Comparison of internal adaptation of bulk-fill and increment-fill resin composite materials. Oper Dent. 2019;44(1):E32-E44. doi: 10.2341/17-269-L.

33-Bayne SC, Thompson JY, Swift EJ, Stamatiades P, Wilkerson M. A characterization of first-generation flowable composites. J Am Dent Assoc. 1998;129(5):567-77.

34- Swapna MU, Koshy S, Kumar A, Nanjappa N, Benjamin S, Nainan MT. Comparing marginal microleakage of three Bulk Fill composites in class II cavities using confocal microscope: an in vitro study. J Conserv Dent. 2015;18(5):409-13. doi: 10.4103/0972-0707.164058

35- Benetti AR, Havndrup-Pedersen C, Honoré D, Pedersen MK, et al. Bulk-fill resin composites: polymerization contraction, depth of cure, and gap formation. Oper Dent. 2015;40(2):190-200.

36- Campos EA, Ardu S, Lefever D, Jassé FF, Bortolotto T, Krejci I. Marginal adaptation of class II cavities restored with bulk-fill composites. J Dent. 2014;42(5):575-81. doi: 10.1016/j.jdent.2014.02.007 37- Braga RR, Ferracane JL. Alternatives in polymerization contraction stress management. Crit Rev Oral Biol Med. 2004;15(3):176-84. 38-Nie J, Yap AU, Wang XY. Influence of shrinkage and viscosity of flowable composite liners on cervical microleakage of class II restorations: a micro-CT analysis. Oper Dent. 2018;43(6):656-64. doi: 10.2341/17-091-L

39- Alomari QD, Reinhardt JW, Boyer DB. Effect of liners on cusp deflection and gap formation in composite restorations. Oper Dent. $2001 ; 26(4): 406-11$.

40- Han SH, Sadr A, Shimada Y, Tagami J, Park SH. Internal adaptation of composite restorations with or without an intermediate layer: effect of polymerization shrinkage parameters of the layer material. J Dent. 2019;80:41-8. doi: 10.1016/j.jdent.2018.10.013 